\title{
МОДЕЛЬ ФОРМИРОВАНИЯ ИННОВАЦИОННОГО АГРОПРОМЫШЛЕННОГО КЛАСТЕРА В КАБАРДИНО-БАЛКАРСКОЙ РЕСПУБЛИКЕ
}

\author{
Шидов А.X., \\ Гедгафова И.Ю., \\ Казиева Б.В.
} ФГБОУ ВО «Кабардино-Балкарский университет им. Х.М. Бербекова», г. Нальчик, Россия

Формирование кластеров рассматривается в статье как основное направление развития инновационной деятельности в агропромышленном комплексе Кабардино-Балкарской республики. Предложена модель формирования инновационного агропромышленного кластера для КабардиноБалкарской республики.

Ключевые слова: агропромышленный комплекс, кластер, регион, инновации, инвестиции, экономика.

В условиях растущей глобализации, взаимозависимости экономик стран мира, обострения глобальной конкуренции за ресурсы (как правило, за интеллект) и рынки сбыта кластерные модели повсеместно признаются одним из важнейших направлений функционирования экономики, включая аграрную сферу.

Россия как полноправная страна мирового сообщества не остается в стороне от общего прогресса и от освоения кластерных моделей. Кластеры все активнее используются в нормативных документах, концепциях, инвестиционных и целевых программах на федеральном и региональном уровнях. Например, в Кабардино-Балкарской республике Распоряжением Правительства КБР от 30.04.2019 № 251-рп была утверждена Стратегии социально-экономического развития Кабардино-Балкарской Республики до 2040 года, в которой говориться, что от состояния и развития агропромышленного кластера зависит не только продовольственная и финансовая обеспеченность жителей республики, но и социальноэкономическое развитие территории в целом [1].

Кластерная форма интеграции принципиально отличается и от вертикально-интегрированных агрохолдингов, и от территориальных производственных формирований. Управление рассматриваемыми категориями также имеет существенные различия. Совет кластера управляет и координирует взаимодействия, входящих в него субъектов по согласованным направлениям их деятельности. В агрохолдингах реализуется жесткая иерархическая система планирования и управления, а также корпоративное взаимодействие входящих в него субъектов. Важно, что кластеры не являются организационно-правовой формой и сохраняют хозяйственную и юридическую самостоятельность 
входящих в них участников в отличие от агрохолдингов, где происходит полная или частичная утрата самостоятельности их участников.

Кластеры - это особая культура в среде предпринимателей, которым присущи не формальные связи с представителями бизнес сообщества и другими сферами процесса производства (наукой, властью и др.), а новое кооперационное мышление [2]. Благодаря этому кластерный конкурентный подход в экономике дает возможность отслеживать всю причинноследственную цепочку, начиная от целевой установки организации предпринимательской или какой-либо другой деятельности до способов удовлетворения потребностей конечного получателя продукции, работ или услуг. Формирование агропромышленного кластера может осуществляться следующими взаимосвязанными путями, а именно:

- на объективной основе с учетом реального развития АПК и системы взаимоотношений в этом секторе экономики;

- на субъективной основе в соответствии с целенаправленным воздействием государственных и муниципальных органов управления, хозяйствующих субъектов или общественных организаций.

При наличии кластероориентированной направленности многих региональных целевых программ и существующей сдерживающей агропродовольственной политики в нашей стране процесс целенаправленного формирования агропромышленных кластеров осуществляется не так быстро и широко, как представлялось в начале кластерного движения. Кроме того, по мнению Козлова М.П. [2] ситуация усугубляется неразработанностью методологии создания и развития конкурентоспособных кластеров. К настоящему времени в процессе формирования агропромышленных кластеров накопился ряд проблем, которые заключаются в следующем [3]:

- по существу отсутствует специальная законодательная и нормативноправовая база по созданию и функционированию агрокластеров, а между тем в Федеральном законе от 29.12.2006 г. № 264-Ф3 «О развитии сельского хозяйства» понятие кластера отсутствует;

- вопросам формирования агропромышленных кластеров в федеральных и региональных программных документах уделено совершенно недостаточно внимания. Так, в Государственной программе развития сельского хозяйства и регулирования рынков сельскохозяйственной продукции, сырья и продовольствия на 2013-2020 годы поставлен вопрос о формировании территориальных кластеров и их государственной поддержке на условиях софинансирования частичного возмещения затрат по формированию региональных мясных и молочных продовольственных кластеров. Причем это касается лишь отдельных регионов страны, а о других видах кластеров там ничего не говорится;

- до сих пор не проработаны организационные структуры и методические инструменты управления созданием агропромышленных кластеров и вопросы формирования ценовых, финансово-кредитных, производственно- 
экономических, информационных и других отношений и взаимодействий между участниками кластерных структур;

- не разработаны и не приняты официальные методические рекомендации и инструктивные документы по формированию и функционированию агропромышленных кластеров.

Несмотря на отмеченные сложности, кластерная модель с успехом используется в различных регионах страны в целях обеспечения устойчивого роста и повышения конкурентоспособности национальной и региональной экономики, а существующие кластерные подходы используются как ключевые элементы при разработке стратегии экономического развития.

Для построения современной кластерно-инновационной системы необходимым условием является соответствие отношений основных участников инновационного развития принципам тройной спирали (ТС). Понимание кластерного взаимодействия в современной науке оформилось в виде концепции «Triple Helix» (тройная спираль) Г. Ицковица, в которой ключевые элементы - наука, бизнес и государство образуют в динамике своего взаимодействия тройную спираль. Тройственная координация обуславливает выполнение участниками ранее не свойственных им функций. Так, если традиционная функция бизнеса заключается во внедрении инноваций, а функция университетов - в производстве знаний и технологий, то в свою очередь роль государства заключается в установлении и регулировании отношений участников [3].

Модель тройной спирали адекватно определяет и направляет взаимоотношения участников инновационной системы, а именно власти (государства), бизнеса и университетов. В мире не существует ни одного примера, где бы национальная инновационная система действовала эффективно вне принципов тройной спирали и где бы университеты находились не в центре этих событий. К этому следует также добавить, что инновация - это более широкий процесс, чем сфера деятельности любой отдельной организации или государства. Основой творческого развития общества является сеть взаимодействий между университетами, предприятиями и государством, играющими одновременно свою традиционную роль и еще роль другую в различных комбинациях. А в целом модель тройной спирали, которую мы получаем в результате - это новая глобальная система инноваций [4]. Заметим, что в настоящее время в условиях экономических санкций и противостояния РФ с западноевропейскими странами, США, Австралией и др. многие субъекты РФ декларировали использование кластерного подхода для развития регионального АПК. Однако изучение их содержания дает все основания утверждать, что разработка предложений по улучшению сложившейся ситуации пока не выходит за рамки отраслевого подхода. Например, типичной является ситуация, когда регион запланировал сформировать агропромышленный или аграрно-инновационный кластер, охватывающий всю совокупность предприятий регионального АПК. Однако, как свидетельствует мировой опыт, полноценный кластер все же должен иметь ярко выраженную 
специализацию. В этой связи в методологическом контексте кластеризации необходимо, прежде всего, выявить территории опережающего развития (ТОР) по производству и переработке конкретных видов сельхозпродукции, которые должны в идеале охватывать несколько соседних районов.

Одним из основных критериев для отнесения к ним должен выступать уровень конкурентоспособности производства сельхозпродукции, а он в свою очередь может быть измерен при помощи таких показателей, как коэффициент специализации и коэффициент душевого производства, при этом целесообразно их рассматривать в динамике за последние 3-5 лет. На основе полученной информации и отмеченных критериев отбора можно будет идентифицировать и локализовать агропромышленные кластеры на территории страны, а также сделать сравнительную оценку их потенциалов. Это позволит формировать полноценные кластеры с использованием ресурсов всех заинтересованных сторон. Это могут быть следующие инициативы: проекты по стимулированию спроса на агропромышленную продукцию местного производства за счет бюджетных субсидий; создание центров компетенций и инжиниринга; развитие инфраструктуры хранения и рыночного продвижения агропромышленной продукции; разработка новых образовательных программ и целевая подготовка специалистов; организация консультационных центров. Все это даст возможность концентрировать ресурсы на ликвидацию «узких мест» в развитии кооперационных связей между участниками кластера.

C учетом накопленного опыта по методологии создания и функционирования региональных агропромышленных кластеров, а также, учитывая специфику развития АПК Кабардино-Балкарской республики, можно предложить модель формирования агропромышленного кластера в республике, состоящую из четырех этапов.

На первом (подготовительном) этапе следует разработать структурную модель агропромышленного кластера Кабардино-Балкарской республики. Группа предприятий, организаций и производств объединяется в некоммерческое партнерство или ассоциацию, создается координационный совет, при этом сами предприятия, фирмы и производства остаются юридически независимыми. На этом этапе необходимо выделить:

1) ядро кластера (основные отрасли или структуры, формирующие кластер, по значимости в организационном процессе или по доле в объеме продукции АПК);

2) тело кластера (вспомогательные отрасли и агросервисное обслуживание.

На втором (аналитическом) этапе выявляются и анализируются общие проблемы развития предприятий, организаций и различных производств, возможные точки быстрого роста, перспективы формирования рынка, обозначаются границы кластера. Кроме того, определяются лидеры, составляется совместный план деятельности, проводится стратегический анализ выявленной модели кластера, выделяются его сильные и слабые стороны, намечается проект развития кластера. На этом этапе разработки приоритет 
должен быть нацелен на экономический механизм с учетом важности административных, организационных и правовых аспектов функционирования кластера и его участников.

Третий этап создания кластера (организационно-экономический) предполагает формирование единой модели кластера, разработку рекомендаций по обеспечению эффективного функционирования кластера, включая мероприятия по его государственной поддержке. В этой связи на данном этапе следует определить масштаб совместной деятельности участников агропромышленного кластера в Кабардино-Балкарской республике, разработать и закрепить функции за отдельными структурами кластера, обосновать концепцию развития кластера.

Четвертый этап включает оценку эффективности деятельности функционирующего кластера. Данный этап предусматривает разработку сценария долгосрочного устойчивого функционирования и развития кластера, в том числе прогноза его функционирования по отдельным районам КабардиноБалкарской республики, обоснование методики оценки эффективности деятельности кластера с точки зрения выявления синергетического эффекта и его вклада в стратегию развития республики.

На этом заключительном этапе осуществляется активное продвижение продукции на более выгодные рынки сбыта, включая создание ассортиментного бренда продукции кластера, достигается устойчивое его функционирование и достижение критической массы участников кластера и его максимальной доли на рынке. При этом предусматривается, что на каждом из указанных этапов формирования кластера в Кабардино-Балкарской республике должна осуществляться государственная поддержка инициатив снизу. Заметим также, что разработка концепции и программы дальнейшего развития агропромышленного кластера в республике должны быть увязаны со стратегическими задачами социально-экономического развития КабардиноБалкарской республики в целом.

\section{Исследование выполнено при финансовой поддержке РФФИ в рамках научного проекта №18-010-00947.}

\section{Список литературы}

1. Стратегия социально-экономического развития КабардиноБалкарской Республики до 2040 года. Распоряжение Правительства Кабардино-Балкарской Республики от 30.04.2019 г. № 251-рп.

2. Козлов М.П. Кластерный подход как механизм активизации инновационного развития субъектов агропромышленного производства // Экономика, труд, управление в сельском хозяйстве. М., 2015. - №1(22). - С. 28-24.

3. Региональные агропромышленные кластеры: методические аспекты формирования и развития в условиях инновационной экономики // Сборник статей Международной научно-практической конференции «Прорывное 
развитие экономики России: условия, инструменты, эффекты», проведенная при поддержке РФФИ (грант 18-010-20078), Ч.2, Нальчик, 2018. - С. 48-54

4. Ицковиц Г. Тройная спираль. Университеты - предприятия государство. Инновации в действии (перевод с англ. Уварова А.Ф.). Томск, издво госуниверситета, 2010. - 238c. 